\title{
SILVER NANOPARTICLES AS APROMISING TREATMENT FOR BLASTOCYSTIS HOMINIS IN EXPERIMENTALLY INFECTED MICE BY
}

HALA M. EL-ASKARY ${ }^{1 *}$, MOUSA A. M. ISMAIL ${ }^{2}$, ENAS Y. ABU-SAREA ${ }^{1}$, EMAN M. FAROUK ${ }^{1}$, EMAN SAYED EL-WAKIL ${ }^{3}$, MOHAMED A. EL-BADRY ${ }^{4}$, AMIRA RAAFAT ${ }^{2}$, MARWA M. AHMED ${ }^{5}$ AND SHIMAA S. IBRAHIM ${ }^{1}$

Department of Parasitology ${ }^{1}$, Faculty of Medicine, Beni-Suef University, Department of MedicalParasitology', Faculty of Medicine, Cairo University, Department of

Parasitology ${ }^{3}$,Theodor Bilharz Research Institute, Research Institute of Medical

Entomology ${ }^{4}$, General Organization for Teaching Hospitals and Institutes (GOTHI),

Giza, and Department of Pathology ${ }^{5}$, Faculty of Medicine, Beni-Suef University

Egypt ( ${ }^{*}$ correspondence: halaelaskary@hotmail.com)

\begin{abstract}
Blastocystis is an opportunistic parasite causes gastro-intestinal symptoms including irritable bowel syndrome (IBS). This study evaluated the effect of probiotics and silver nanoparticles on Blastocystis hominis in mice and compared between both probiotics (Lactobacillus) and silver nanoparticles as compared to metronidazole. A cross-sectional study was done in which stool samples were collected from patients suffering from IBS.The stool samples were examined microscopically to detect B. hominis and any co-parasitism. All positive stool samples were cultured on Modified Jones' media. BALB/C mice were infected by isolated Blastocystis. The effect of probiotics and silver nanoparticles on blastocystosis was tested in experimentally infected mice. Cysts' mean count in stool of infected mice markedly decreased; with a decrease in serum levels of nitric oxide and glutathione antioxidants compared to drug control one. There wasintestinal villi improvement of infected groups treated with probiotics and silver nanoparticles, with mild inflammation and decrease of Blastocystis at the intestinal surface as compared to theinfected group metronidazole treated.
\end{abstract}

Keywords: Blastocystis hominis, Irritable bowel syndrome, Nanoparticles, Probiotics.

\section{Introduction}

Blastocystis spp. is a common intestinal parasite in humans. Blastocystosis prevalence was high in developing countries (53.8\%) than in developed ones (3.3\%). Pathogenic of $B$. hominis is unconvincing; due to contradictory reports and that the organism was found in both asymptomatic and symptomatic individuals (Khademvatan et al, 2017). It was considered as a commensal fecal organism (Mohamed et al, 2017).

Blastocystis spp. is a unicellular, obligate, anaerobic protozoan found in the gastrointestinal tract of humans; many other vertebrates and invertebrates act as a reservoir host (Yan et al, 2007). In Egypt, the prevalence has reached up to $50 \%$ and it has four main forms, which are vacuolar, granular, and amoeboid, and can be found in culture while cysts are found in the stool. Transmission of the parasite occurs through the fecooral route mainly in people with poor envi- ronmental sanitation with frequent exposure to animals and contaminated food also it may pass unnoticed or might be accompanied by many symptoms like nausea, vomiting, abdominal cramps, fatigue, and diarrhea especially in children and immunocompromised patients(Sari et al, 2018).

Diagnosis of Blastocystis spp. by examination of stool samples was a routine method in many laboratories, by ordinary methods, e.g. saline smear method, formalin-ether method, and trichrome stain method (Nithyamathi et al, 2016). Blastocystis spp. was considered to stand for a direct or indirect cause of gastrointestinal symptoms including inflammatory bowel syndrome (IBS) (Scanlan, 2012).

IBS is a functional gastrointestinal disorder, with prevalence rates $(35 \%-43 \%)$ in developing countries and (5\%-24\%) in developed countries (Lepczyńska et al, 2016). The proposed mechanism in IBS included 
the low-grade inflammation caused by the constant immune activation induced by Blastocystis (Coyle et al, 2012). The IgG antibody levels to $B$. hominis were significantly higher in patients with IBS than in asymptomatic controls (Hussain et al, 1997). Metronidazole is the most commonly used drug for the treatment of Blastocystis infection. The dosage in adults ranges from 250$800 \mathrm{mg}, 3$ times a day for 10 days or can be given in combination with other drugs such as paramomycin (Pasqui et al, 2004), cotrimoxazole (Andiran et al, 2006) or trimethoprim-sulfamethoxazole (Stensvold et al, 2008). In pediatric treatment, metronidazole is prescribed based on the patient's body weight at the dosage of $20-30 \mathrm{mg} / \mathrm{kg} / \mathrm{day}$ (Kurt et al, 2016). Treatment failure of metronidazole has been reported as early as in 1976 (Zierdt and Tan, 1976). Regardless of being the first line of treatment for blastocystosis, the metronidazole efficacy ranged from $0 \%$ to $100 \%$ with varied effective dosages (Coyle et al, 2012). Many studied the efficacy of different drugs and respective regimens on patients (Roberts et al, 2014).

The probiotics are living microbes feed supplement that successfully affects the host by improving its intestinal balance. Nowadays, probiotics are considered quite every day in health-promotion "functional foods" for humans. Additionally, they are therapeutic and prophylactic growth supplements in animal production and human health also other common probiotics include yeasts and spore-forming Bacillus spp. They have adhesion abilities; produce bio-activated molecules, which provide immune stimulation (Duc et al, 2004). Studies also hold an added interest in probiotics, as they can be kept in spore form and be stored on the shelf (Barbosa et al, 2005).

Nanoparticles (NPs) have intrinsic properties related to size, distribution, and morphology that can improve their optical, electronic, catalytic, and magnetic features (Silva et al, 2013; Bhosale et al, 2014). A promising mechanism of parasite growth inhibition was by stimulating the function of the immune system; another mechanism is by producing cellular oxidative stress in microbes; also it induces morphological and structural changes in the parasites and another way is by binding to the cell membrane of the infected cell (Abaza et al, 2016). Thus, they have a very important role in diagnosis and treatment of diseases because of their larger surface areas in relation to the bulk material (Qasim et al, 2014; Akbari et al, 2017).

Silver nanoparticles, chitosan, and oxidized metals have growth inhibitory or cytotoxic effects on parasites as Giardia, Leishmania, Plasmodium, Toxoplasma and insect larvae (Elmi et al, 2013). The silver nanoparticles silver ions, and silver nanoparticles contained complexes antimicrobial behavior with a high ability to inactivate viruses and bacteria (Jebali and Kazemi, 2013; Catalano et al, 2016). Silver nanoparticles are excellent nano-carriers for anti-parasitic drug, but their effect on $B$. hominis has not been widely explored (Sun et al, 2019).

The present study aimed to assess the effect of probiotics and silver nanoparticles on Blastocystis hominis infected mice and compared the effect of both probiotics and silver nano-particles with the traditional metronidazole treatment.

\section{Patients and Methods}

This is a cross-sectional study, in which stool samples were collected from patients suffering from IBS attending the Tropical medicine department, Beni-Suef University Hospital. Related demographic and clinical data were obtained. All stool samples were microscopically examined using iodine wet mount before and after formalin ethyl acetate concentration and permanent trichrome staining to detect $B$. hominis and any co-parasitism. All positive stool samples were cultured for Blastocystis using Modified Jones' media. Isolated B. hominis was used for animal experiments; mice were infected intraoesophageal with previously prepared 10,000 Blastocystis cyst.

Laboratory bred Swiss Albino mice, CD-I 
strain 3-5 weeks old, weighing 20-25g, were used and divided into 2 main groups: the control group (GI) and tested group (GII). Control group (GI) consisted of three subgroups of 8 mice each; negative control (Non-infected, non-treated) subgroup (GIA), positive control (infected, non-treated) subgroup (GIB,) and drug control (infected and treated with metronidazole as $10 \mathrm{mg} / \mathrm{kg} /$ day given 3 weeks after proving Blastocystis infection for seven consecutive days) subgroup (GIC) (Becker et al, 2011). Tested group (GII) consisted of two subgroups, each containing 8 mice; Blastocystis spp. infected, treated with single daily dose of 10 billion probiotic lactobacilli for one week (GIIA) (Becker et al, 2011; El-Sayed et al, 2017) and $B$. hominis infected, treated with a single daily dose of $50 \mathrm{mg} / \mathrm{kg}$ silver nanoparticles for one week (GIIB). All infected mice subgroups were treated 3 weeks post-infection to ensure the establishment of infection.

The anti-Blastocystis effect of silver nanoparticles, probiotics and metronidazole, treated mice were sacrificed after cessation of treatment was assessed by: 1 Parasitological examination of stool: Fresh fecal pellets from the large intestine of each mouse were collected separately and examined daily then the mean numbers of the cysts were calculated at the $21^{\text {st }}$ day PI (to assess infection establishment) and $28^{\text {th }}$ day PI (one week post-treatment) before mice scarification, according to each group. Each fecal sample was suspended in $7 \%$ formalin and homogenized; 50 microns of the solution was examined microscopically and the number of
Blastocystis cysts was counted. 2- Biochemical assessment: Antioxidants level, both sera glutathione peroxidase nitric oxide (NO), were calorimetrically determined according to the kits manual from Elabscience, Inc. 3Histopathological studies: Jejunum, proximal $2 \mathrm{~cm}$ of ileum, and large intestine were fixed in $10 \%$ neutral buffered formalin followed by immersion in xylene then impregnated in paraffin. 4-mm thick section was taken from each block and stained with hematoxylin and eosin for evaluation (Bancroft and Stevens, 1990).

Determination of serum glutathione peroxidase activity: Glutathione Peroxidase (GSH-Px) promoted reaction of hydrogen peroxide $\left(\mathrm{H}_{2} \mathrm{O}_{2}\right)$ and reduced glutathione to give $\mathrm{H}_{2} \mathrm{O}$ \& oxidized glutathione (GSSG). Glutathione reductase (GR) catalyzes NADPH to reduce GSSG and produce GSH, $\&$ NADPH was oxidized to NADP+ at same time. NADPH has a specific absorbance peak at $340 \mathrm{~nm}$, while NADP+ didn't. GSHPx activity can be calculated according to the changing rate of absorbance value. Calculation: Oxidation amount of $1 \mathrm{nmol}$ of NADPH catalyzed by $1 \mathrm{ml}$ of sample per minute was defined as 1 unit. GSH-Px activity $(\mathrm{nmol} / \mathrm{min} / \mathrm{ml})=\Delta \mathrm{A} \times 536$

Determination of serum nitric oxide: $\mathrm{NO}$ was easily oxidized to $\mathrm{NO}_{2}$ - in vivo or in aqueous solution, and a reddish azo compound formed with color developing agent, and the concentration of azo compound was linearly related to the NO concentration. The concentration of $\mathrm{NO}$ was calculated indirectly by measuring the OD value at $550 \mathrm{~nm}$.

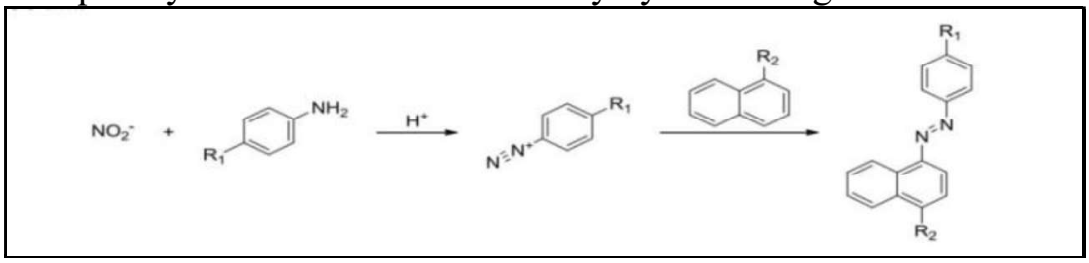

Calculations: Nitrite in sample

$$
(\mu \mathrm{mol} / \mathrm{L})=\begin{gathered}
\text { A sample } \\
\text { A standard }
\end{gathered} \times 50
$$


Statistical analysis: Data were coded and entered using the statistical package for the Social Sciences (SPSS), version 26 (IBM Corp., Armonk, NY, USA). Data were done as mean and SD for quantitative variables and frequencies (number of cases) and relative frequencies (percentages) for categorical variables. Comparisons between groups were done by (ANOVA) analysis with multiple comparisons post hoc (Chan, 2003a). For comparing categorical data, Chi square test was used. Exact test was used instead when the expected frequency was less than 5 (Chan, 2003b). $P$ values less than 0.05 were significant.

\section{Results}

Mean number of cysts in positive control non-treated subgroup (GIB) was 2810 cysts with $\mathrm{SD}=33.91$, while the mean count in the infected group treated with metronidazole (GIC) was 2214 cyst with $\mathrm{SD}=32.02$. The mean number of cysts detected in infected subgroup treated by probiotics (Lactobacillus) (GIIA) was 1999 cyst with $\mathrm{SD}=35.78$ and their mean number in infected subgroup, treated by silver nanoparticles (GIIB) was 700 cysts with $\mathrm{SD}=27.39$.

There was a decrease in mean parasiticcount in all infected treated subgroups com- pared to positive infected non-treated controlsubgroup. This was marked and statistically significant in the infected group treated by silver nanoparticles (GIIB) and in the infect- ed group treated by probiotics (GIIA) with $(\mathrm{p}<0.001)$ as compared to infected group treated with metronidazole (GIC).

The mean level of serum NO was 58.72 with $\mathrm{SD}=7.74$ in infected positive non-treated control (GIB) and 41.26 with $\mathrm{SD}=5.3$ indrug control subgroup treated with metroni- dazole (GIC). The mean $\mathrm{NO}$ was 37.86 with $\mathrm{SD}=$ 2.17 in infected group treated with Lac-tobacillus (GIIA); and was 30.70 with $\mathrm{SD}=1.03$ in infected subgroup treated with silver nanoparticles (GIIB). A significant decrease of mean level of serum NO of infected treated mice with silver nanoparticles and probiotics compared to infected mice metronidazole treated $(P<0.001)$.

Mean titer of serum glutathione in non-treat- ed mice (GIB) was 209.6 with $\mathrm{SD}=31.21$ \& reduced to 148.82 with $\mathrm{SD}=19.40$ in serum of metronidazole control treated (GIC). Cysts count decreased by $28.86 \%$, \& $75.09 \%$ in GIIA (treated by probiotics) and GIIB (treated by silver nanoparticles) respectively; compared to $21.21 \%$ of GIC (treated by metronidazole). Activity of serum NO was significantly decreased by $35.54 \%$, \& $47.73 \%$ in GIIA \& GIIB, respectively compared to $29.75 \%$ in GIC.

Serum glutathione level was reduced by $36.78 \%$ in GIIA \& $39.44 \%$ in GIIB compared to $29 \%$ in GIC. Decrease serum glutathione titer was more in infected mice treated with Lactobacillus (GIIA) \& silver nanoparticles (GIIB) $132.5 \&$ \& 126.93, respectively compared to infected mice treated with metronidazole with significance $(p<0.001)$.

Microscopic examination of small and large intestine sections from negative control mice (GIA) showed normal mucosa, while that of positive control mice (GIB) showed variable degree of villous atrophy with moderate congestion of submucosal capillaries associated with moderate edema, heavy infections of intestinal lumen with vacuolatedform of $B$. hominis and marked inflammatory cells infiltrates with predominant eosinophils. Large intestinal mucosa of GIB showed moderate capillaries congestion, edema with inflammatory cell infiltrates; more large intestinal lumen showed heavy $B$. hominis infections surrounded by inflammatory cells.

Section from small intestine of GIC (metronidazole) showed villous atrophy with short broad villi distended with moderate inflammatory cell infiltrates without $B$. hominis. By microscopy large intestinal section showed mild inflammatory cell infiltrated with mild submucosal edema and congested capillaries without $B$. hominis. Small intestine of infected treated with probiotics showed normal intestinal villi with edema and mild inflammatory cell infiltrates associated with mild congestion with absence of $B$. hominis while large intestine showed moderate edema and mild congestion with the absence of $B$. hominis. Small intestine ofinfected, treated with silver nanoparticles showed normal intestinal villi without 
inflammation, congestion, edema or B. hom- nal mucosa with the absence of inflammation, inis, but large intestine showed normal intesti- congestion, edema and B. hominis.

Details were given in tables $(1,2,3,4,5, \& 6)$ and figures $(1,2,3,4,5,6,7, \& 8)$.

Table 1: Comparison between mean number of cysts of Blastocystis hominis in stool and standard deviation in groups:

\begin{tabular}{|l|l|l|l|l|l|l|l|l|l|}
\hline \multirow{2}{*}{$\begin{array}{l}\text { Blastocystis hominis } \\
\text { in stool }\end{array}$} & (GIB) & GIC) & GIIA) & (GIIB) & \\
& Mean & SD & Mean & SD & Mean & SD & Mean & SD & $P$ Value \\
\hline & 2810.00 & 33.91 & 2214.00 & 23.02 & 1999.00 & 35.78 & 700.00 & 27.39 & $K 0.001 *$ \\
\hline
\end{tabular}

*Significant $(p<0.05)$

Table 2: Correlation of Blastocystis hominis cysts count in stool between groups (Post hoc pair wise comparisons)

\begin{tabular}{|l|l|l|l|l|}
\hline & (GIB) & (GIC) & (GIIA) & (GIIB ) \\
\hline (GIB) & & $<0.001$ & $<0.001$ & $<0.001$ \\
\hline (GIC) & $<0.001$ & & $<0.001$ & $<0.001$ \\
\hline (GIIA) & $<0.001$ & $<0.001$ & & $<0.001$ \\
\hline (GIIB) & $<0.001$ & $<0.001$ & $<0.001$ & \\
\hline \multicolumn{5}{|c|}{} \\
\hline
\end{tabular}

Table 3: Mean level and standard deviation of nitric oxide and glutathione peroxidase in sera of different groups.

\begin{tabular}{|c|c|c|c|c|c|c|c|c|c|c|c|}
\hline \multirow[t]{2}{*}{ Colormetry } & \multicolumn{2}{|c|}{ (GIA) } & \multicolumn{2}{|c|}{$(\mathrm{GIB})$} & \multicolumn{2}{|c|}{ (GIC) } & \multicolumn{2}{|c|}{ (GIIA) } & \multicolumn{2}{|c|}{ (GIIB) } & P Value \\
\hline & Mean & SD & Mean & SD & Mean & $\mathrm{SD}$ & Mean & SD & Mean & $\mathrm{SD}$ & \\
\hline Nitric Oxide & 25.78 & 0.65 & 58.73 & 7.74 & 41.26 & 5.3 & 37.86 & 2.17 & 30.70 & 1.03 & $<0.001$ \\
\hline Glutathione peroxidase & 112.31 & 11.91 & 209.60 & 31.21 & 148.82 & 19.4 & 132.5 & 9.80 & 126.93 & 14.39 & $<0.001$ \\
\hline
\end{tabular}

*Significant $(p<0.05)$

Table 4: Correlation of antioxidants serum levels between all groups

\begin{tabular}{|c|c|c|c|c|c|c|}
\hline Colormetry & & (GIA) & (GIB) & (GIC) & (GIIA) & (GIIB) \\
\hline \multirow{5}{*}{$\begin{array}{l}\text { Nitric Oxide } \\
(\mathrm{NO})(\mu \mathrm{mol} / \mathrm{l})\end{array}$} & (GIA) & & $<0.001$ & 0.011 & 0.069 & 1.000 \\
\hline & (GIB) & $<0.001$ & & $<0.001$ & $<0.001$ & $<0.001$ \\
\hline & (GIC) & 0.011 & $<0.001$ & & 1.000 & 0.024 \\
\hline & (GIIA) & 0.069 & $<0.001$ & 1.000 & & 0.276 \\
\hline & (GIIB) & 1.000 & $<0.001$ & 0.024 & 0.0276 & \\
\hline \multirow{5}{*}{$\begin{array}{l}\text { Glutathione peroxidase } \\
(\mathrm{nmol} / \mathrm{min} / \mathrm{m})\end{array}$} & (GIA) & & $<0.001$ & 0.428 & 1.000 & 1.000 \\
\hline & (GIB) & $<0.001$ & & 0.002 & $<0.001$ & $<0.001$ \\
\hline & (GIC) & 0.428 & 0.002 & & 1.000 & 1.000 \\
\hline & (GIIA) & 1.000 & $<0.001$ & 1.000 & & 1.000 \\
\hline & (GIIB) & 1.000 & $<0.001$ & 1.000 & 1.000 & \\
\hline
\end{tabular}

Table 5: B. hominis reduction count in stool of infected treated groups and mean level of serum NO and glutathione peroxidase in all infected groups compared to control positive group

\begin{tabular}{|l|c|c|c|}
\hline Variables & (GIC) & (GIIA) & $(\mathrm{GIIB})$ \\
\hline Number of Blastocystis hominis cysts in stool & $21.21 \%$ & $28.86 \%$ & $75.09 \%$ \\
\hline Colormetry Nitric Oxide $(\mathrm{NO})(\mu \mathrm{mol} / \mathrm{l})$ & $29.75 \%$ & $35.54 \%$ & $47.73 \%$ \\
\hline Colormetry Glutathione peroxidase $(\mathrm{nmol} / \mathrm{min} / \mathrm{ml})$ & $29.00 \%$ & $36.78 \%$ & $39.44 \%$ \\
\hline
\end{tabular}

$$
\text { *Significant }(p<0.05)
$$

Table 6: Degree of congestion, inflammation, oedema and count of Blastocystis cysts in intestine of test groups and control positive subgroup and Silver nanoparticles infected treated and probiotics compared to infected Metronidazole treated

\begin{tabular}{|c|c|c|c|c|c|c|c|c|c|c|}
\hline \multirow{2}{*}{\multicolumn{2}{|c|}{ Variables }} & \multicolumn{2}{|c|}{ (GIB) } & \multicolumn{2}{|c|}{ (GIC) } & \multicolumn{2}{|c|}{ (GIIA) } & \multicolumn{2}{|c|}{ (GIIB) } & \multirow[t]{2}{*}{$\mathrm{P}$ value } \\
\hline & & Count & $\%$ & Count & $\%$ & Count & $\%$ & Count & $\%$ & \\
\hline \multirow[t]{4}{*}{ Congestion } & Absent & 0 & 0.0 & 0 & 0.0 & 1 & 20 & 5 & 100 & \multirow[t]{4}{*}{$<0.001$} \\
\hline & Mild & 0 & 0.0 & 3 & 60 & 2 & 40 & 0 & 0.0 & \\
\hline & Moderate & 4 & 80 & 2 & 40 & 2 & 40 & 0 & 0.0 & \\
\hline & Sever & 1 & 20 & 0 & 0.0 & 0 & 0.0 & 0 & 0.0 & \\
\hline \multirow{4}{*}{$\begin{array}{l}\text { Lymphocytic } \\
\text { Infiltration }\end{array}$} & Absent & 0 & 0.0 & 0 & 0.0 & 2 & 20 & 4 & 80. & \multirow[t]{4}{*}{------ } \\
\hline & Mild & 0 & 0.0 & 2 & 40 & 1 & 20 & 1 & 20 & \\
\hline & Moderate & 4 & 80 & 2 & 40 & 2 & 40 & 0 & 0.0 & \\
\hline & Sever & 1 & 20 & 1 & 20 & 0 & 0.0 & 0 & 0.0 & \\
\hline \multirow{4}{*}{$\begin{array}{c}\text { Inflamma- } \\
\text { tory } \\
\text { Edema }\end{array}$} & Absent & 0 & 0.0 & 1 & 20 & 2 & 20 & 5 & 100 & \multirow[t]{4}{*}{$<0.001$} \\
\hline & Mild & 1 & 20 & 2 & 40 & 1 & 20 & 0 & 0.0 & \\
\hline & Moderate & 4 & 80 & 2 & 40 & 2 & 40 & 0 & 0.0 & \\
\hline & Sever & 0 & $0 \%$ & 0 & 0.0 & 0 & 0.0 & 0 & 0.0 & \\
\hline \multirow{4}{*}{$\begin{array}{c}\text { Number of } \\
\text { Blastocystis } \\
\text { Hominis }\end{array}$} & Absent & 0 & 0.0 & 3 & 60 & 4 & 80 & 5 & 100 & \multirow[t]{4}{*}{$<0.001$} \\
\hline & Little & 0 & 0.0 & 2 & 40 & 1 & 20 & 0 & 0.0 & \\
\hline & Moderate & 1 & 20 & 0 & 0.0 & 0 & 0.0 & 0 & 0.0 & \\
\hline & Heavy & 4 & 80 & 0 & 0.0 & 0 & 0.0 & 0 & 0.0 & \\
\hline
\end{tabular}




\section{Discussion}

Blastocystosis is an unusual enteric protozoan parasite of humans and many animals of worldwide distribution (Tan, 2008). It has been reported in Jordan (Nimri and Batchoun, 1994), Kuwait (Zaki et al, 1991), Qatar (Abu-Madi et al, 2015), UAE (Abu-Odeh et $a l$, 2019), Saudi Arabia (Mohamed et al, 2017), as well as many Egyptian authors (Khalifa, 1999; Mahmoud and Saleh, 2003; El Shazly et al, 2006; Fouad et al, 2011; Elghareeb et al, 2015; El Saftawy et al, 2019). Metronidazole was the first golden $B$. hominis treatment (Sekar and Shanthi, 2013), but, with side effects, treatment failure, and parasitic resistance (Rajamanikam et al, 2019).

In the present study, the probiotics and silver nanoparticles compared to metronidazole on in experimentally infected mice showed a decrease in mean parasitic count in all infected \& treated groups compared to infected, non-treated, positive control group. This was marked and significant in the infected subgroups treated by probiotics or silver nanoparticles in compared to the infected metronidazole treated ones $(\mathrm{p}<0.001)$. This agreed with Boorom et al. (2008) who reported of metronidazole failure treatment of symptomatic patients and recommended the natural plant extracts alone or combined with metronidazole.

Consequently, search for bioactive plants which can be used as non-conventional antiparasitic treatment received attention in recent times due to the increasing worldwide development of resistance to chemical drugs in parasitic populations (Abouel-Nour et al, 2016), particularly those with phenolic contents (Abdel-Hady et al, 2014). Sawangjaroen and Sawangjaroen (2005) in Thailand found that $3 / 7$ plants extracts, the dichloromethane and methanol extracts from the $\mathrm{Br}$ ucea javanica seed and a methanol extract from Quercus infectoria nut gall gave the highest activity at a concentration of 2000 microg $/ \mathrm{mL}$, them killed $82,75 \& 67 \%$ of the B. hominis samples and inhibited 94, $100 \&$ $76 \%$ of them, respectively, and the metha- nol extracts from the Brucea javanica seed and a methanol extract from Quercus infectoria nut gall showed highest activity at a concentration of $2000 \mathrm{microg} / \mathrm{mL}$, them killed $82,75 \& 67 \%$ of the $B$. hominis samples and inhibited 94, $100 \& 76 \%$, respectively. Bremer et al. (2015) in Denmark found that six ethanolic out of 24-plant extracts showed significant anti-Blastocystis activity. Mallotus oppositifolius gave good activity as the reference anti-protozoal drug MTZ. El-Bali et al. (2020) in Egypt used Salvadora persi$c a$ to treat three virulent subtypes of Blastocystis $\mathrm{sp}$. and recommended their evaluation in vivo.

The probiotics (viable microbial organis$\mathrm{ms}$ ) in treatment of specific infections was evolved into a fundamental option, with immune-modulating properties and enhance mucosal barrier, they can have a significant influence on the treatment and prevention of disease (Termmathurapoj et al, 2004).

In the current study, the Lactobacillus was combatable to metronidazole and Saccharomyces boulardii probiotics have potential beneficial effects on $B$. hominis symptoms and presence. This agreed with Dinleyici et al. (2011). Also, when lauric acid was given alone or combined with metronidazole on experimental giardiasis with its anti-giardial activity was better compared to metronidazole (Rayan et al, 2007). Thus, nano-biotechnology in treating parasites was due to the unique properties of nanoparticles as the reached nanomaterials size $(10-100 \mathrm{~nm})$ as the size of most biological structures, so enhance the penetration of the drug to various body tissues (Norouzi, 2017). It was best used in treatment of malaria (Barabadi et al, 2019).

Others investigated the inhibitory activity of various concentrations of silver nanoparticles and curcumin nanoparticles on $B$. hominis in vitro (Ahmed et al, 2015). The effect of silver nanoparticles and curcumin nanoparticles was significantly higher than metronidazole through different incubation periods, and that the effect of the single 
therapy was better than the combined silver nanoparticles and curcumin nanoparticles (El-Sayed et al, 2017). Also, silver nanoparticles have many inhibitory and cytotoxic effects on many parasites such as Giardia, Toxoplasma, Leishmania, Plasmodium, and even insect larvae (Elmi et al, 2013). As to disinfection ability of silver nanoparticles on Cryptosporidium parvum oocysts in vitro confirmed the in vivo results study, and the magnitude reduction in oocyst shedding in mice fed on silver nanoparticles treated oocysts when compared with the control (Su et al, 2014). Besides, both silver nanoparticles and silver ions significantly decreased Cryptosporidium oocysts viability, in a dose-dependent manner, between concentrations of $0.005 \& 500 \mu \mathrm{g} / \mathrm{ml}$, as assessed by an excystation assay and the shell/sporozoite ratio, were statistically significant at $500 \& 5000$ $\mu \mathrm{g} / \mathrm{ml}$ (Cameron et al, 2015).

In the present study; there was a significant decrease in mean level of both serum nitric oxide and glutathione peroxidase in all infected treated mice compared to infected not treated ones $(<0.001)$. A significant decrease in nitric oxide and glutathione peroxidase mean level was reported in the infected mice treated with probiotics Lactobacillus and silver nanoparticles compared to the infected mice treated with metronidazole $(<0.001)$.

This agreed with Eida et al. (2008) who an in vivo study detected high levels of NO in mice infected with $B$. hominis isolated from symptomatic patients compared to low changes in the control. Also, this agreed with Saran et al. (2004) who studied Trichomonas vaginalis and found that the mean level of NO was significantly higher in severe symptomatic than moderate and mild symptomatic ones. Steinert et al. (2010) found that noninvasive, lumen-dwelling, extracellular pathogens as Giardia and Blastocystis rarely come in contact with macrophages, but in close immediacy to NO producing enterocytes, and thus survived the hostile environment, and suppressed intestinal epithelial NO production.

These suggested the diverse pathogenic roles of Blastocystis spp. isolates from different clinical presentations, with variation in growth kinetics and metronidazole sensitivity of Blastocystis spp. isolated from different clinical asymptomatic and symptomatic patients (Ahmed et al, 2018). There was a higher oxidative protein damage intensified the antioxidant processes associated with blastocystosis in improving host immune-modulating strategies (Tan et al, 2013).

Undoubtedly, oxidative stress was increasingly relevant as a significant clinical and biochemical mechanism of pathogenicity that oxidative stress functions against the pathogens was the first line of defense and immune response, with high metabolic rate of the rapidly growing, multiplying parasites producing high free radicals by-products (Becker et al, 2004). Parasitic infection and IBS contributed to oxidative stress independently and when present together, the oxidative stress burden may be increased (Elnekave et al, 2003).

In the present histopathological examination of jejunum, ileum, and large intestine of Blastocystis infected positive controls showed a profound effect on the structure of intestinal mucosa. This effect was in the form of moderate numbers of Blastocystis cysts with a moderate degree of inflammation, congestion, and lymphocytic infiltration metronidazole treated mice. But, mild numbers of Blastocystis cysts with a mild degree of inflammation, congestion and lymphocytic infiltration were in infected mice treated with probiotics. This effect was nearly absent in infected mice silver nanoparticles treated seen as some epithelial damage and mucosal sloughing. So, B. hominis infected mice exhibited severe goblet cell hyperplasia. This agreed with Santos and Rivera (2009) who found that goblet cells were one of the potential host antiparasitic defense mechanisms against blastocystosis. 
Yason et al. (2019) in Singapore found that particular isolates of Blastocystis ST7 caused changes in microbiota populations and potentially lead to an imbalance of the gut microbiota. This study suggested that certain isolates of Blastocystis exert their pathogenic effects through disruption of the gut microbiota and provides a counterpoint to the increasing reports indicating the commensal nature of this ubiquitous parasite. Also, a study on experimental giardiasis, which found that treatment with metronidazole, lauric acid, and Lactobacillus improved pathology in the form of partial healing of intestinal mucosa, mild shortening, and thickening of the villi, with few Giardia trophozoites in the lumen (Amer et al, 2007).

Younis et al. (2020) in Egypt assessed the efficacy of silver nanoparticles (Ag Nps) alone and combined with metronidazole (Ag $\mathrm{Nps}+\mathrm{MTZ}$ ) as potential alternative therapeutic agents for $B$. hominis. They found There was a statistically significant difference $(P<0.05)$ in the in vitro growth inhibition of the parasite over the different time intervals when using the tested drugs against the control drug.

The present histopathological examination of infected controls showed a profound effect on intestinal mucosa, in the form of villous atrophy, and infiltration of lamina propria with inflammatory cells. Also, B. hominis vegetative forms were detected in intestinal lumen between villi. Pathology was in some epithelial damage and mucosal sloughing that agreed with Phillips and Zierdt (1976). Also, Blastocystis infected mice showed severe goblet cell hyperplasia, one of the host anti-Blastocystis defense mechanisms (Santos and Rivera, 2009).

\section{Conclusion}

Detection of $B$. hominis in patient' stools complained of IBS played an important role in pathogenesis.

Silver nanoparticles proved better than probiotics and metronidazole in treatment of $B$. hominis and both of them were better than metronidazole alone.

\section{References}

Abaza, SM, 2016: Applications of nanomedicine in parasitic diseases. P. U. J. 9: 1-6.

Abouel-Nour, MF, El-Shewehy, DMM, Hamada, SF, Morsy, TA, 2016: The efficacy of three medicinal plants; garlic, ginger and mirazid and a chemical drug metronidazole against $\mathrm{Cry}$ ptosporidium parvum: ii- Histological changes. J. Egypt. Soc. Parasitol. 46, 1:185-200

Abu-Madi, M, Aly, M, Behnke, JM, Clark, C G, Balkhy, H, 2015: The distribution of Bast-ocystis subtypes in isolates from Qatar. Parasit Vectors 8:465-9.

Abdel-Hady, NM, El-Hela, AA, Morsy, TA, 2014: Phenolic content of some selected Lamiaceous Egyptian medicinal plants: Antioxidant potential and ecological friend mosquito-larvicidal. J. Egypt. Soc. Parasitol. 44, 1:21-4.

Abu-Odeh, R, Ezzedine, S, Madkour, M, Stensvold, CR, Samie, A, et al, 2019: Molecular subtyping of Blastocystis from diverse animals in the United Arab Emirates. Protist 170, 5: 1256-79.

Ahmed, MAF, Ismail, KA, Ahmed, SAEG, Ibrahim, AN, Gohar, YM, 2015: In vitro activity of curcumin and silver nanoparticles against Blastocystis hominis. Infect. Dis. Clin. Pract. 23:135-40.

Ahmed, MM, Habib, FS, Abdel-Fattah, NS, Saad, GA, EI Naggar, HM, 2018: Growth kinetics and metronidazole sensitivity of Blastocystis spp. isolated from colorectal carcinoma (CRC) and non-CRC patients. Egypt. J. Hosp. Med. 1:3850-6.

Akbari, M, Oryan, A, Hatam, G, 2017: Application of nanotechnology on treatment of leishmaniasis: A review. Acta Trop. 172:86-90.

Amer, NM, Mahmoud, SS, Helmy, A, Hammam, $\mathbf{O}, 2007$ : The role of probiotics in controlling Giardia intestinalis in experimental animals. N. Egypt. J. Med. 37:13-23.

Andiran, N, Acikgoz, ZC, Turkay, S, Andiran, F, 2006: Blastocystis hominis: An emerging and imitating cause of acute abdomen in children. J. Pediatr. Surg. 41, 8:1489-91.

Bancroft, J D, Stevens, A, 1990: Theory and practice of histological techniques Trop. Parasitol. 3, 1:17-25.

Barabadi, H, Alizadeh, Z, Rahimi, MT, Barac, A, Maraolo, AE, et al, 2019: Nanobiotechnology as an emerging approach to combat malaria: A systematic review. Nanomedic. 18:221-33. 
Barbosa, TM, Serra, CR, La Ragione, RM, Woodward, MJ, Henriques, AO, 2005: Screening for bacillus isolates in the broiler gastrointestinal tract. Appl. Environ. Microbiol.71:96878.

Becker, K, Tilley, L, Vennerstrom, JL, Roberts, D, Rogerson, S, Ginsburg, H, 2004: Oxidative stress in malaria parasite-infected erythrocytes: host-parasite interactions. Inter. J. Parasitol. 34, 2:163-89.

Becker, S, Hoffman, P, Houpt, ER, 2011: Efficacy of anti-amebic drugs in a mouse model. Am. J. Trop. Med. Hyg. 84:581-6.

Bhosale, RR, Kulkarni AS, Gilda S, Aloorkar NH, Osmani, RA, Harkare, BR, 2014: Innovative eco-friendly approaches for green synthesis of silver nanoparticles. Int. J. Pharm. Sci. Nanotech. 7:2328-37.

Boorom, KF, Smith, H, Nimri, L, Viscogliosi, E, Spanakos, G, et al, 2008: Oh my aching gut: Irritable bowel syndrome, Blastocystis, and asymptomatic infection. Parasit. Vectors 1:40-6.

Bremer, C, Soelberg, J, Stensvold, CR, Jäger, AK, 2015: Activity of medicinal plants from Ghana against the parasitic gut protist Blastocystis. J. Ethnopharmacol. 174: 569-75

Cameron, P, Gaiser, BK, Bhandari, B, 2015: Silver nanoparticles decrease the viability of $\mathrm{Cr}$ yptosporidium parvum oocysts. Appl. Environ. Microbiol. 82, 2:431-7.

Catalano, PN, Pezzoni, M, Costa, C, Soler, GJA, Bellino, MG, et al, 2016: Optically transparent silver-loaded mesoporous thin film coating with long-lasting antibacterial activity. Micropo. Mesopo. Mater. 236:158-66.

Chan, YH, 2003a: Biostatistics102: Quantitative data, parametric \& non-parametric tests. Singapore Med. J. 44, 8:391-6.

Chan, YH, 2003b: Biostatistics 103: Qualitative data-tests of independence. Singapore Med. J. 44, 10:498-503.

Coyle, CM, Varughese, J, Weiss, LM, Tanowitz, HB, 2012: Blastocystis: To treat or not to treat. Clin. Infect. Dis. 54:105-10.

Dinleyici, EC, Eren, M, Dogan, N, Reyhanioglu, S, Yargic, ZA, Vandenplas, Y, 2011: Clinical efficacy of Saccharomyces boulardii or metronidazole in symptomatic children with Blastocystis hominis infection. Parasitol. Res. 108, 3: 541-5.

Duc le, H, Hong, HA, Barbosa, TM, Henriques, AO, 2004: Cutting SM. Characterization of bacillus probiotics available for human use. Appl Environ Microbiol .70:2161-71.

Eida, OM, Hussein, EM, Eida, AM, El-Moamly, AA, Salem, AM, 2008: Evaluation of the nitric oxide activity against Blastocystis hominis in vitro and in vivo. J. Egypt. Soc. Parasitol. 38, 2:521-36.

El-Bali, MA, Abdulhakim, A, Mohamed, RT, El-Malky, MA, Bakri, RA, et al, 2020: Antiprotozoal potential of Salvadora persica against 3 virulent subtypes of Blastocystis sp. J. Parasit. Dis. 44, 4:694-701.

Elghareeb, AS, Younis, MS, EI Fakahany, A F, Nagaty, IM, Nagib, MM, 2015: Laboratory diagnosis of Blastocystis spp. in diarrheic patients. Trop Parasitol. 5, 1:36-41.

Elmi, T, Gholami, S, Fakhar, M, Azizi, F, 2013: A Review on the seof nanoparticles in the treatment of parasitic infections. J. Mazand. Univ. Med. Sci. 23, 102:126-33.

Elnekave, K, Siman Tov, R, Ankri, S, 2003: Consumption of L-arginine mediated by Entamoeba histolytica L-arginase (EhArg) inhibits amoebicidal activity and nitric oxide production by activated macrophages. Parasite Immunol. 25: 597-608.

El Saftawy, EA, Amin, NM, Hamed, DH, Elkazazz, A, Adel, S, 2019: The hidden impact of different Blastocystis genotypes on C-3 and IgE serum levels: a matter of debate in asthmatic Egyptian children. J. Parasit. Dis. 43, 3:443-51

El-Sayed, AH, Amer, N, Ismail, S, Ali, I, Rizk, $\mathbf{E}$, et al, 2017: In vitro and in vivo Anti-Blastocystis efficacy of olive leaf extract and bee pollen compound. Res. J. Parasitol. 12, 2:33-44.

El Shazly, AM, Awad, SE, Sultan, DM, Sadek, GS, Khalil, HH, Morsy TA, 2006: Intestinal parasites in Dakahlia Governorate, with different techniques in diagnosing protozoa. J. Egypt. Soc. Parasitol. 36, 3:1023-34.

Fouad, SA, Basyoni, MM, Fahmy, RA, Kobaisi, MH, 2011: The pathogenic role of different Blastocystis hominis genotypes isolated from patients with irritable bowel syndrome. Arab J. Gastroenterol. 12, 4:194-200

Hussain, R, Jaferi, W, Zuberi, S, 1997: Significantly increased IgG2 subclass antibody levels to Blastocystis hominis to patients with irritable bowel syndrome. Am. J. Trop. Med. Hyg. 56: 301-6.

Jebali, A, Kazemi, B, 2013: Nano-based antileishmanial agents: A toxicological study on na- 
noparticles for future treatment of cutaneous leishmaniasis. Toxicol. In-vitro 27:1896-904.

Khademvatan, S, Masjedizadeh, R, Rahim, F, Mahbodfar, H, Salehi R, et al, 2017: Blastocystis and irritable bowel syndrome: Frequency and subtypes from Iranian patients. Parasitol. Inter. 66, 2:142-15.

Khalifa, AM, 1999: Diagnosis of Blastocystis hominis by different staining techniques. J. Egypt. Soc. Parasitol. 29:157-65.

Kurt, O, Al FD, Tanyuksel, M, 2016: Eradication of Blastocystis in humans: Really necessary for all? ParasitolInter. 65, 6Pt:B797-801.

Lepczyńska, M, Dzika, E, Kubiak, K, Korycińska, J, 2016: The role of Blastocystis spp. as an etiology of irritable bowel syndrome. Polish Ann. Med. 23, 1:57-60.

Mahmoud, MS, Saleh, WA, 2003: Secretory \& humoral antibody responses to Blastocystis hominis in symptomatic and asymptomatic human infections. J. Egypt. Soc. Parasitol. 33, 1:13-30. Mohamed, AM, Ahmed, MA, Ahmed, SA, AlSemany, SA, Alghamdi, SS, et al, 2017: Predominance and association risk of Blastocystis hominis subtype I in colorectal cancer: A case control study. Infect. Agents Canc. 12:21-6.

Mohamed, RT, El-Bali, MA, Mohamed, AA, Abdel-Fatah, MA, El-Malky, et al, 2017: Subtyping of Blastocystis sp. isolated from symptomatic and asymptomatic individuals in Makkah, Saudi Arabia. Parasit. Vectors 10, 1:174.

Nimri, L, Batchoun, R, 1994: Intestinal colonization of symptomatic and asymptomatic schoolchildren with Blastocystis hominis. J. Clin. Microbiol. 32, 11:2865-6.

Nithyamathi, K, Chandramathi, S, Kumar, S, 2016: Predominance of Blastocystis spp. infection among school children in Peninsular Malaysia. PLoS One 11, 2:e136709.

Norouzi, R, 2017: A review on most nanoparticles applied against parasitic infections. J. Biol. Todays World 6,10:196-203.

Pasqui, AL, Savini, E, Saletti, M, Guzzo, C, Puccetti, L, Auteri, A, 2004: Chronic urticaria and Blastocystis hominis infection: A case report. Euro Rev. Med. Pharmacol. Sci. 8:117-20. Phillips, BP, Zierdt, CH, 1976: Blastocystis hominis: Pathogenic potential in human patients and in gnotobiotes. Exp. Parasitol. 39, 3:358-64.

Qasim, M, Lim, D, Park, H, Na, D, 2014: Nanotechnology for diagnosis and treatment of infectious diseases. J. Nanosci. Nanotechnol. 14: 7374-87.
Rajamanikam, A, Hooi, HS, Kudva, M, Samudi, C, Kumar, S, 2019: Resistance towards metronidazole in Blastocystis sp.: A pathogenic consequence. PloS one, 14, 2:e 0212542.

Rayan, H, Ismail, OE, Gayar, E, 2007: Prevalence and clinical features of $D$. fragilis infection in patients suspected to have intestinal parasitic infection. J. Egypt Soo Parasitol. 37:599-608.

Roberts, T, Stark, D, Harkness, J, Ellis, J, 2014: Update on the pathogenic potential and treatment options for Blastocystis sp. Gut Pathogens. 6:17. https://doi.org/10.1186/1757-4749-6. Santos, HJ, Rivera, WL, 2009: Kinetic analysis of antibody responses to Blastocystis hominis in sera and intestinal secretions of orally infected mice. Parasitol. Res. 105:1303-10.

Saran, M, Beck-Speier, I, Fellerhoff, B, Bauer, G, 2004: Phagocytic killing of microorganisms by radical processes: consequences of the reaction of hydroxyl radicals with chloride yielding chlorine atoms. Free Radic. Biol. Med. 26: 482-90.

Sari, IP, Benung, MR, Wahdini, S, Kurniawan, A, 2018: Diagnosis and identification of $B l$ astocystis subtypes in primary school children in Jakarta. J. Trop. Pediatr. 117, 8:2585-90.

Scanlan, PD, 2012: Blastocystis: Past pitfalls and future perspectives. Trends Parasitol. 28: 327-34.

Sekar, U, Shanthi, M, 2013: Blastocystis: Consensus of treatment and controversies. Trop. Parasitol. 3, 1:35-9.

Silva, ATB, Coelho, AG, Merkoçi, A, Martins, MVA, Crespilho, FN, et al, 2013: Nanoassembled supramolecular films from chitosanstabilized gold nanoparticles and cobalt (II) phthalocyanine. J. Braz. Chem. Soc. 24:1237-45.

Sawangjaroen, N, Sawangjaroen, K, 2005: The effects of extracts from anti-diarrheic Thai medicinal plants on the in vitro growth of the intestinal protozoa parasite: Blastocystis hominis. J. Ethnopharmacol. 98, 1:67-72.

Steinert, JR, Chernova, T, Forsythe, ID, 2010: Nitric oxide signaling in brain function, dysfunction and dementiall. Neuroscientist 16:435-52.

Stensvold Arendrup, MC, Nielsen, HV, Bada, A, Thorsen, S, 2008: Symptomatic infection with Blast-ocystis spp. subtype 8 successfully treated with trimethoprim-sulfamethoxazole. Ann. Trop. Med. Para-sitol. 102, 3:271-4.

Su, YH, Tsegaye, M, Varhue, W, 2014: Quantitative dielectrophoretic tracking for characteri- 
zation and separation of persistent subpopulations of Cryptosporidium parvum. Anal. 139:6673.

Sun, Y, Chen, D, Pan, Y, 2019: Nanoparticles for antiparasitic drug delivery. Drug Deliv. 26, 1:1206-21.

Tan, KS, Mirza, H, Teo, JD, Wu, B, Macary, PA, 2013: Current views on the clinical relevance of Blastocystis spp. Curr. Infect. Dis. Rep. 12: 28-35.

Tan, KSW, 2008: New insights on classification, identification, and clinical relevance of Blastocystis sp. Clin. Microbiol. Rev. 21, 4:639-65.

Termmathurapoj, S, Leelayoova, S, Aimpun, P, Thathaisong, U, Nimmanon, T, et al, 2004: The usefulness of short-term in vitro cultivation for the detection and molecular study of Blastocysis hominis in stool specimens. Parasitol. Res. 93, 6:445-7.
Yan, Y, Su, S, Ye, J, 2007: Blastocystis spp. subtype 5: A possibly zoonotic genotype. Parasitol. Res. 101, 6:1527-32.

Yason, JA, Liang, YR, Png, CW, Zhang, Y, Tan, KSW, 2019: Interactions between a pathogenic Blastocystis subtype and gut microbiota: in vitro and in vivo studies. Microbiome 7, 1:30-8.

Younis, MS, Abououf, EA, Ali, AE, Abd Elhady, SM, Wassef, RM, 2020: In vitro effect of silver nanoparticles on Blastocystis hominis. Int. J. Nanomedicine 15:8167-73.

Zaki, M, Daoud, AS, Pugh, RN, al-Ali, F, alMutairi, G, et al, 1991: Clinical report of Blastocystis hominis infection in children. J. Trop.

Med. Hyg. 94, 2:118-22.

Zierdt, CH, Tan, H, 1976: Ultrastructure and light microscope appearance of Blastocystis hominis in a patient with enteric disease. Zeitschrift Parasitenk. 50, 3:277-83

Fig. 1: Number of Blastocystis hominis in stool of all groups.

\section{Explanation of figures}

Fig. 2: Mean level of serum Nitric Oxide (NO) $\mathrm{nmol} / \mathrm{min} / \mathrm{ml}$ in all groups.

Fig. 3: Mean level of serum glutathione peroxidase $\mathrm{nmol} / \mathrm{min} / \mathrm{ml}$ in all groups.

Fig. 4: Reduction in B. hominis count in stool of infected treated groups and percentage of reduction in mean level of serum NO and glutathione peroxidase in all infected groups in comparison to control positive group.

Fig. 5: Light microscopy of small intestinal section from (A) control group showed normal mucosa, with overview insert box (H\&E stain $\mathrm{x}$ 200). (B) B. hominis infected mice showed variable degree of villous atrophy (red arrows) with moderate congestion of submucosal capillaries (black arrows) associated with moderate edema (H\&E stain x100). (C) Intestinal lumen showed heavy infestations of vacuolated form of B. hominis (red arrow) (H\&E stain $\mathrm{x} 400$ ). (D) Marked inflammatory cells infiltrates with predominant eosinophils (red arrows) (H\&E stain $\mathrm{x} 200)$.

Fig. 6: Light microscopy of small intestinal section (A) metronidazole treated group showed villous atrophy with short broad villi distended with moderate inflammatory cell infiltrates (red arrows) with absence of Blastocystis hominis (H\&E stain x100). (B) Probiotic lactobacilli treated group showed normal intestinal villi with edema and mild inflammatory cell infiltrates (red arrows) associated with mild congestion (black arrows) without $B$. hominis (H\&E stain x200). (C \& D) Sliver nanoparticles treated group showed normal intestinal villi with absence of inflammation, congestion, edema and B. hominis (H\&E stain, x100\& x200).

Fig. 7: Light microscopy of large intestinal section from (A) control group showed normal mucosa, with overview insert box (H\&E stain $\mathrm{x} 100)$. (B) B. hominis infected group, intestinal mucosal showed moderated capillaries congestion (black arrows), edema (red star) with inflammatory cell infiltrates (red arrow) (H\&E stain x100). (C) The mucosa of infected group was disrupted by marked inflammatory cell infiltrates (red arrow) associated with capillaries congestion (black arrow) (H\&E stain x200), and the intestinal lumen showed heavy infestations of vacuolated form of $B$. hominis surrounded by inflammatory cells (red arrows) (D) (H\&E stain x400).

Fig. 8: Light microscopy of large intestinal section from metronidazole treated group showed mild inflammatory cell infiltrates (red arrows) with mild submucosal edema \& congested capillaries (black arrows) without $B$. hominis. (A). (B) Probiotic lactobacilli treated group, mucosa showed moderate edema (red stars) and mild congestion (black arrow) with absence of B. hominis. (C) Sliver nanoparticles treated group showed normal intestinal mucosa with absence of inflammation, congestion, edema and B. hominis (A, B, C H\&E stain x100)

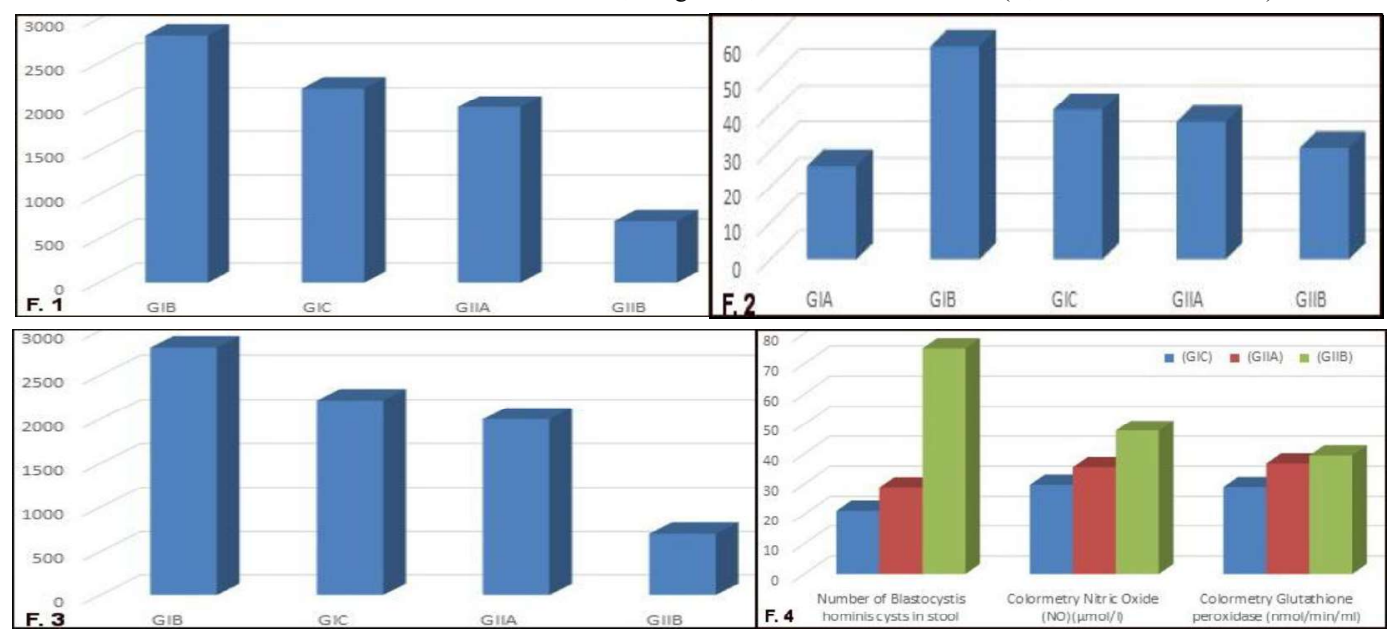



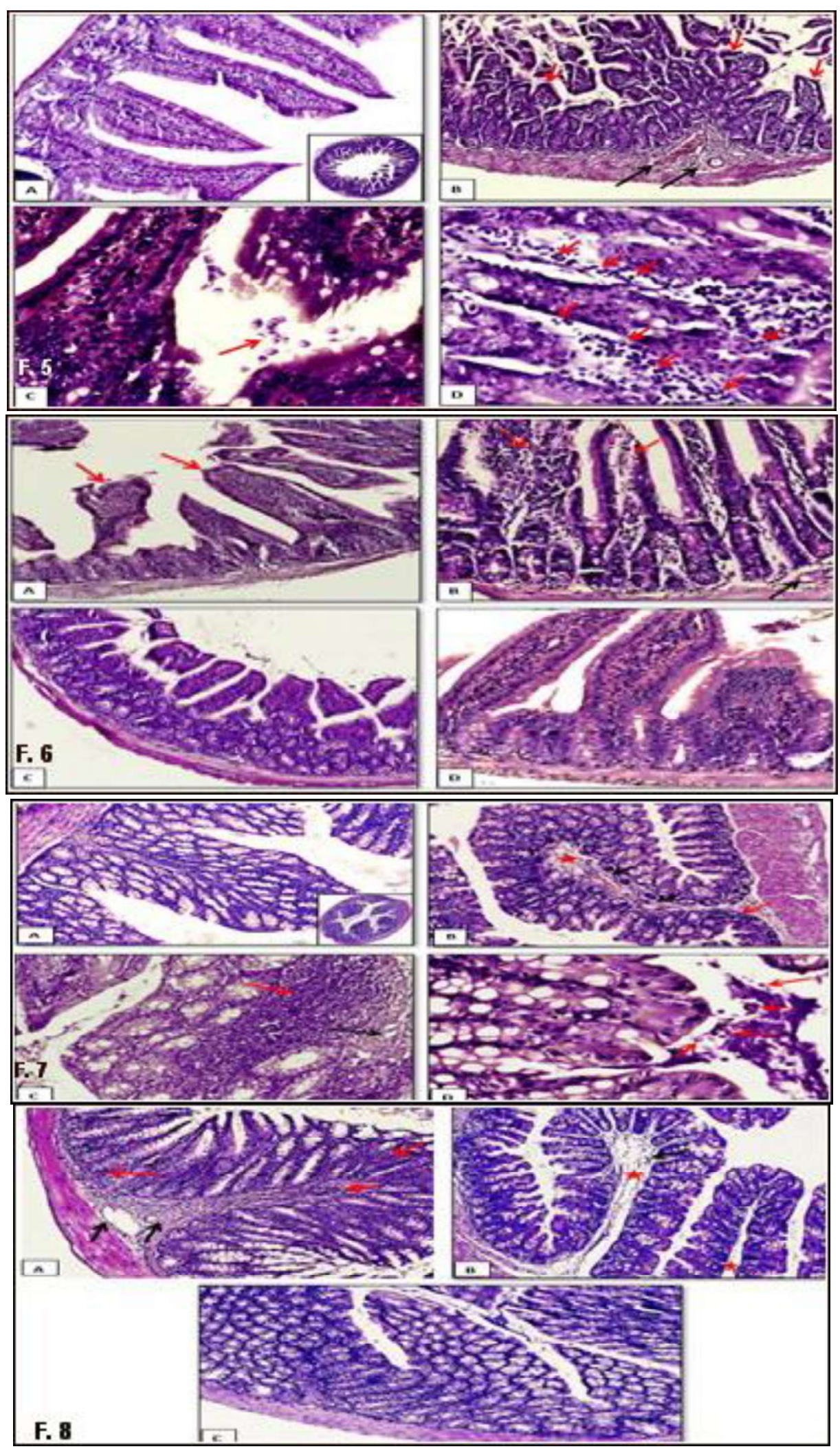